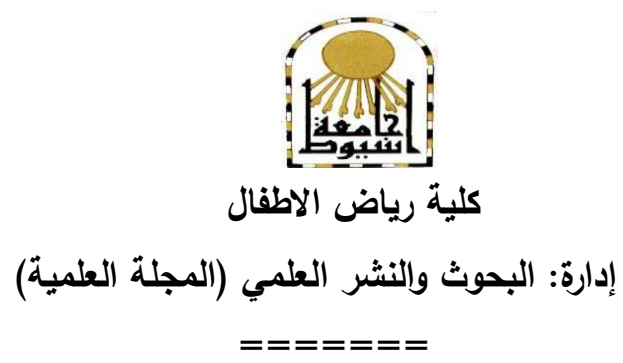

\title{
تأثير مشاهدة برامج الرسوم المتهركة على سلوك أطفال الروضة من وجهه نظر الأمهات
}

\author{
إعـــداد \\ أ.د. كريمان بدير \\ أستاذ ورئيس قسم رياض الأطفال \\ كلية الثرق العربي للاراسات العليا \\ المملكة العربية السعودية \\ أ. هنيره بنت ناصر بن ابراهيم الصوينغ \\ باحث بكلية الثرق العربي

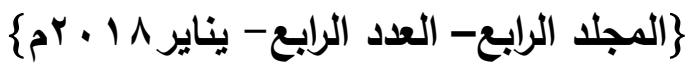


أ.د. كريمان بلدير

أ. منيره بنت ناصر بن ابراهيم الصوينع
تأثير مشاهدة برامج الرسوم المتحركة على سلوك أطفال الروضة من وجهه نظر الأمهات

ملخصص

هدفت الدراسة الم معرفة التأثيرات الإيجابية والسلبية على سلوك أطفال الروضة نتيجة مشاهدة

برامج الكرتون (الرسوم المتحركة وتم تصميم استبانة موجهة للأمهات بالبنود السلبية والايجابية للسلوك وتم

استخدام المنهج الوصفي التحليلي لتحليل نتائج تطبيق الاستبانة والتي تح تطبيقها على (r ا من أمهات

أطفال الروضة ،وأوضحت النتائج وجود إيجابيات الى حد ما في تقليد الطفل لنماذج سلوكيات إيجابية

كما وجدت سلبيات كثيرة نتيجة زيادة ساعات المشاهدة وتؤث سلبياً على جوانب عديدة من سلوك

الطفل وفي ضوء ذلك أوصت الدراسة بتقنين ساعات مشاهدة الطفل للبرامج الالكترونية ومتابعة

مايشاهده الطفل 


\section{Effect of Watching Cartoon Programs on The Behavior of Kindergarten Children from Point of View of Mothers}

\section{Abstract}

The study aimed to identify (role of cartoons in forming behavior ofkindergarten children (negative)، advantages of cartoons in forming behavior of kindergarten children identification if it was relation has significance between watching times number of child for cartoons and between behavior of kindergarten child)، and to achieve these aims the researcher used associative descriptive approach ' as the researcher used questionnaire as a tool for her study. study society formed of mothers of kindergarten children in Riyadh city and model education schools. As study sample represented by random sample its size is (12) mother. Study reached to the following results ( mothers of kindergarten children in Riyadh city see that cartoons effect to some extent in forming negative behavior for kindergarten child، that mothers of kindergarten children in Riyadh city are agrees to some extent ، the results revealed about occurrence of proportional relation has statistically significance between hours number that child spend in watching cartoons and negative behavior)، and the study recommended with (encourage the children to making various activities develop mental and emotional abilities as alternative for watching cartoons programs ، prompting mothers upon importance of reducing period of watching of their children for cartoons). 
تعد وسائل الأعلام من أهم الوسائل التي تسخدم في نقل المعارف والخبرات للمجتمع ككل وفي كافه أنحاء العالم. كما أهما أصبحت من أهم وسائل الاتصال الجماهيري تأثيرا على الأفراد لاسيما الأطفال، وذلك لسهولة بناء شخصية الطفل والتأثير عليها، فتتبلور شخصيته بسهولة وبوقت قصير جدا حسب ما تريد وسيلة الإعلام، ويعتبر التلفزيون من أكثر أدوات الاتصال الجماهيري تأثيرا على الأطفال، ونهاء وذلك لما يحويه من مشاهد، وصور، وألوان، ورسومات، وحركات، وإيحاءات، ورموز، وإشارات عديدة،

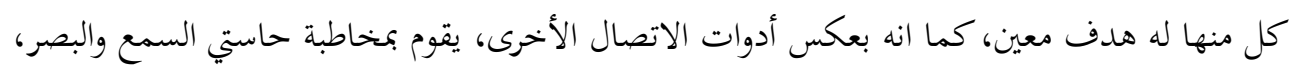
وبالتالي يكون تأثيره أقوى وأسرع من أدوات ووسائل الاتصال الأخرى، كالمذياع مثلا، ولذلك نراه أصبح جزءا هاما يستخدم للمشاركة في عملية التربية، فأصبح ركنا أساسيا في كل منزل.

تكثر مشاهدة الأطفال للرسوم المتحركة ذات القدرة على اجتذاب الطفل من خلال الخيال وبماليات التقنية التي تميزها. فتجعله متسمرا أمام شاشات التلفاز لعدة ساعات يشاهد برابحه المفضلة

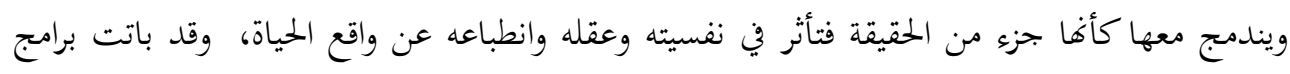
الرسوم المتحركة تشكل مصدر قلق وخوف للأهل فهم يشاهدون أطفالهم يصبحون بحرد دمى تخضع لشروط البحتمع الاستهاكي المحفف.

كما أشار فلاته (1 . . †) "ولبرامج الرسوم المتحركة تأثيرات متعددة على الجوانب المعرفية، والسلوكية للأطفال؛وذلك لأ ن برامج الأطفال تعتمد على الرسوم المتحركة بشكل أساسي، وتأتي أهمية

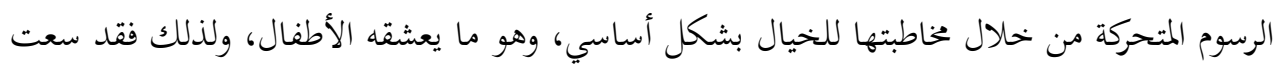
المؤسسات التربوية إلى استثمار ميزان الرسوم المتحركة وجعلها وسيلة تعليمية، وذلك لتحقيق عدد من

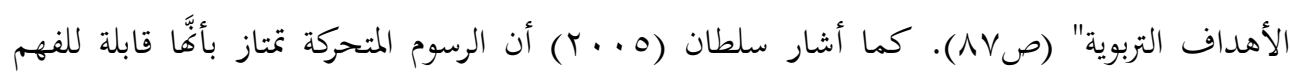
والاستيعاب بسهولة وسرعة، وهذا كّله يجعلها جذَّابة ومشوقة للمتعلمين الأطفال، وبالتالي إمكانية توظيفها في العملية التعليمية.

ولقد علم الغرب أن غالب الأطفال في عالمنا اليوم يتلقون ثقافاتم خاصة قبل المدرسة من الأجهزة الالكترونية التي بدورها تعتبر ناقل للثقافة بحيث تشكل جو\% من مؤثرات الثقافة في حياقم، وغالبها من أفلام الرسوم المتحركة، ماتسمى بأفلام الكرتون، يليها المسلسلات والأفلام ومثالها حتى أصبح لأفلام الكرتون قنوات خاصة تبث طوال اليوم، في قالب فني جذاب متطور، وأنطقوها بلغتنا، فالتصق بها أطفال المسلمين ألتصاقا مخيفا، أثر على تشكيل سلوكهم وعقلياقم، إلى جانب التأثير السلبي على لى لى 


\section{المجلة العلمية لكلية رياض الاطفال - جامعة اسيوط}

صحتهم حيث بتذب الرسوم المتحركة الطفل إلى عوالم مثيرة وتؤثر على علاقاته وسلوكه ومواقفة وعلاقاتة، وتساهم في تكوين شخصيتة، وبذلك تحتل هذه الوسيلة مكانة متميزة لدية، لأفها تقدم له

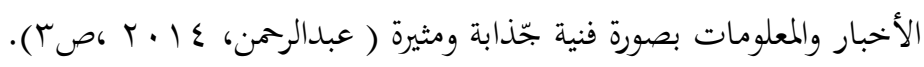

وتسهم الرسوم المتحركة في تكوين وبناء شخصية الأطفال، وذلك لأفا تقدم للطفل المعلومات

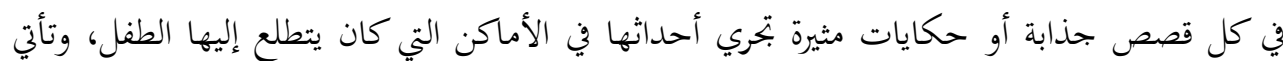
جاذبية الرسوم المتحركة من حركتها الحية التي تستمد عناصرها من واقع الإنسان والحيوان والنبات، والتي تتميز في حرية التعبير.

كما أن الرسوم المتحركة تمتاز بأغا قابلة للفهم والأستيعاب بسهولة وبسرعة، وهذاكلة يجعلها

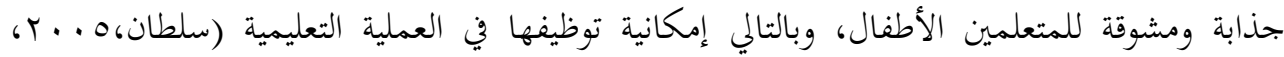

ويساعد توفر عناصر اللون والحركة والصوت والصورة في برامج الرسوم المتحركة في تزويد الأطفال

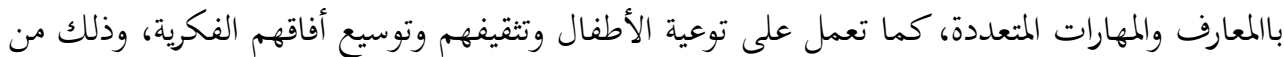

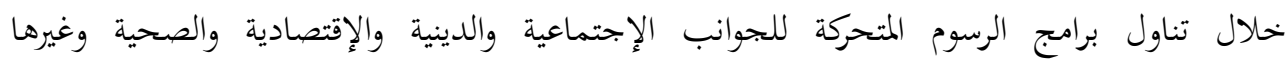

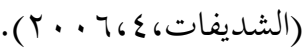

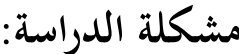

استرعى انتباه الباحثة تقليد أطفال الروضة لبعض الحركات وترديد بعض الكلمات والقيام

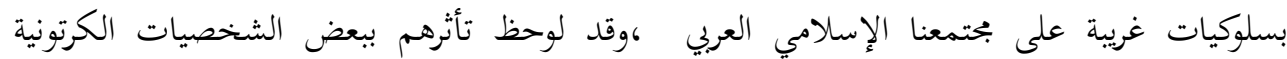

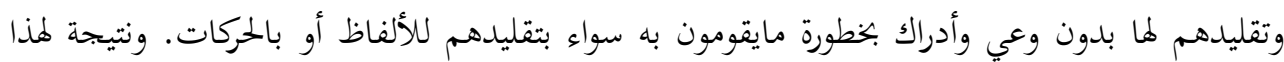

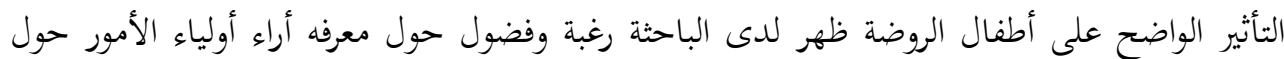
دور برامج الرسوم المتحركة في تشكيل سلوك أطفال الروضة ـ بمراجعة التراث النظري والدراسات المرتبطة هذذا الموضوع حيث أشارت عدة دراسات إلى تأثير الرسوم المتحركه في سلوك أطفال الروضة ومن بين تلك الدراسات دراسة مهدية وأمال (11 ( + ). وبذلك تتحدد مشكلة الدراسة بالأجابة على السؤال التالي: ما

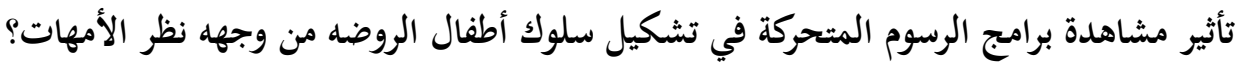


أ.د. كريمان بدير

أ. منيره بنت ناصر بن ابراهيم الصوينع بلدئ
تأثير مشاهدة برامج الرسوم المتحركة على سلوك أطفال الروضة من وجهه نظر الأمهات

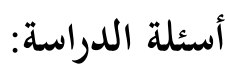

ا - هل توجد علاقة ذات دلاله أحصائية بين مشاهدة الرسوم المتحركة وبين السلوك السلبي لطفل الروضة؟ r- هل توجد علاقة ذات دلاله أحصائية بين مشاهدة الرسوم المتحركة وبين السلوك الإيجابي لطفل الروضة؟ ب- هل توجد علاقة بين مدة مشاهدة الطفل للرسوم المتحركة وسلوكه السلبي في مرحلة رياض الأطفال؟

ع - هل توجد علاقة بين مدة مشاهدة الطفل للرسوم المتحركة وسلوكه الايجابي في مرحلة رياض الأطفال؟

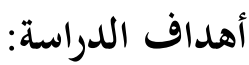
هدف هذا البحث إلى التعرف على:

1 ا ـ دور الرسوم المتحركة في تشكيل سلوك طفل الروضة (السلبي) من وجهة نظر الأمهات.

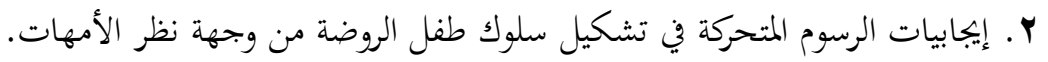

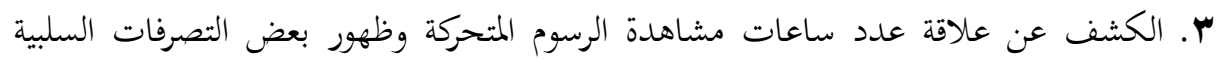

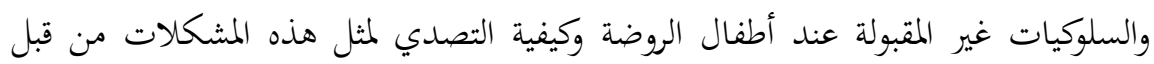
الأسرة والجهات التي لها تأثير على الأعلام والمتصلة بالطفل.

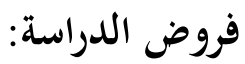

1- توجد علاقة ذات دلاله أحصائية بين مشاهدة الرسوم المتحركة وبين السلوك السلبي لطفل الروضة.

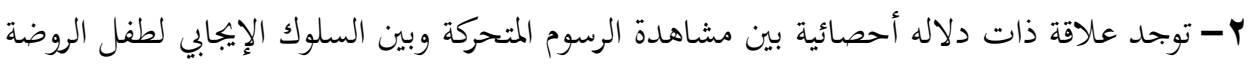

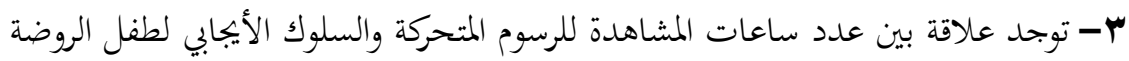
ع - توجد علاقة بين عدد ساعات المشاهدة للرسوم المتحركة والسلوك السبي لطفل الروضة 


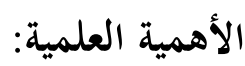

- يضيف البحث إلى التراث النظري دور الوسائط المتعددة والمتمثلة في برامج الرسوم المتحركة لأطفال الروضة ودورها في اكساب سلوكيات محددة للأطفال.

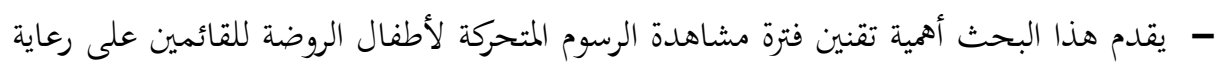

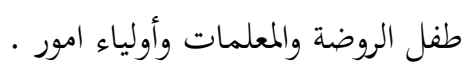

- كما أنه يفيد لمعرفه العلاقه بين مشاهدة البرامج الكرتونية (الرسوم المتحركة) وسلوك أطفال

$$
\text { الروضة. }
$$

- معرفة الأثار الأيجابية من مشاهدة البرامج الكرتونية (الرسوم المتحركة) وتعزيزها ومعرفه الأثار السلبية ومعالجتها.

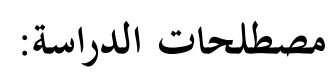

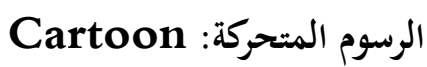

$$
\begin{aligned}
& \text { هي عبارة عن رسومات متتابعة ذات تغيرات طفيفة متهدده ومرتبة لغرض التصوير والعرض على }
\end{aligned}
$$

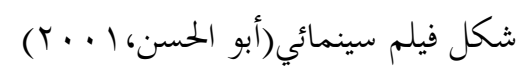

$$
\begin{aligned}
& \text { وتعرف الباحثة الرسوم المتحركة أجرائيا: }
\end{aligned}
$$

بأها بحموعة من الصور المرسومة المتحركة ذات الألوان الجذابة المعدة مسبقا معروضة على

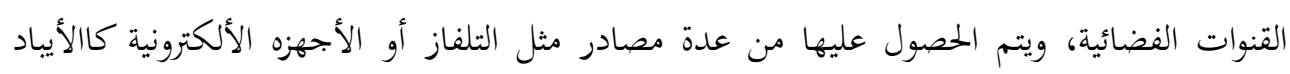

$$
\text { أخ........ }
$$

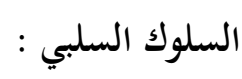

وتعرف الباحثه السلوك السلبي أجرائيا:

هو كل مايقوم به الطفل من فعل أولفظ غيرمرغوب فيه من الآخرين المخالطين للطفل 
وتعرف الباحثة السلوك الأيجابي أجرائيا: هو كل مايقوم به الطفل من فعل أوقول مقبول تفضله الأسرة وأصدقاء الطفل وفي والروضة وتعززه

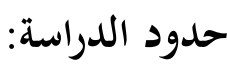
تتحدد حدود هذا البحث في الآتي: الحدود الموضوعية: يقتصر هذا البحث على التعرف على تأثير مشاهدة البرامج الكرتونيه ( الرسوم المتحركه) في تشكيل سلوك أطفال الروضة من وجه نظر الأمهات.

الحدود الزمانية: ترتبط نتائج الدراسة الحالية بالزمن الذي أجريت فية الدراسة وهو الفصل الدراسي

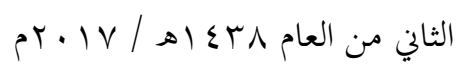
الحدود المكانية: تم تطبق هذا البحث على أمهات اطفال الروضه في مدينة الرياض وفي مدراس التربيه النموذجية.

الحدود البشرية: تم التطبيق على أمهات أطفال الروضة الب أم في مدارس التربية النموذجية بمدينة الرياض.

$$
\text { الدراسات السابقة }
$$

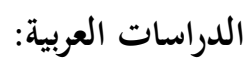

دراسة الحولي ( ع • • ؟ بعنوان "القيم المتضمنة في أفلام الرسوم المتحركة" هدفت هذه الدراسة إلى التعرف على سلبيات وأيجابيات الرسوم المتحركة والتلفزيون على الأطفال من وجهه نظر الأمهات من حيث أفما عنصرين مرتبطين ببعضهما البعض. كما أستخدم الباحث المنهج الوصفي التحليلي، كما كانت عينة الباحث ( · (1) من النساء عشوائيا ممن لديهن أطفال كما أستخدم الباحث أستبانة مفتوحة الأسئلة. ولقد كانت نتائج هذه الدراسة أتفاق رأي البياحئ الأمهات حول سلبيات الرسوم المتحركة من حيث تضمينها للعنف والجريمة، وكذلك أتفاق رأي الأمهات وتحليل المتحوى للأفلام من حيث إيمابياتا في نشر بعض القيم كالتعاون. 


\section{المجلة العلمية لكلية رياض الاطفال - جامعة اسيوط}

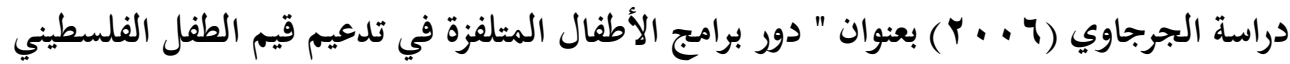

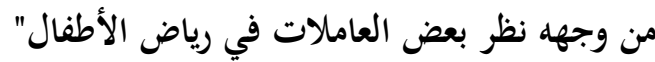

هدفت هذه الدراسة إلى الإشارت إلى عيوب البرامج التلفزيونية المقدمة للأطفال من حيث اها

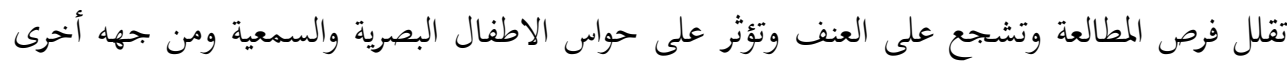

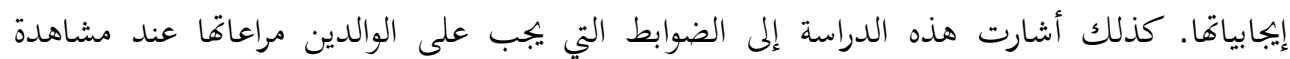

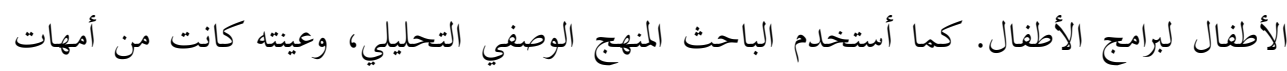

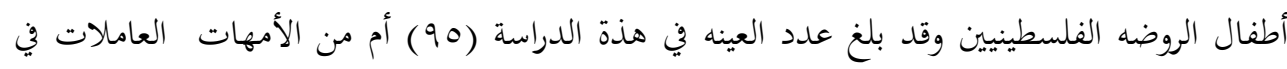

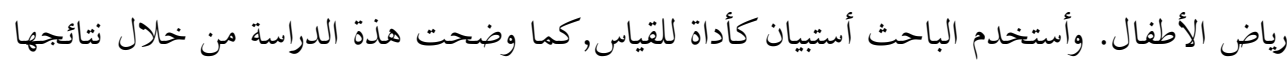

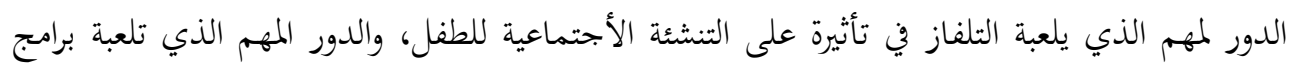
الأطفال في تدعيم القيم العلمية.

أجرى المومني ودولات والشلول (11 + Y) دراسه تجريبية " أثر استخدام الرسوم المتحركة العلمية في تدريس العلوم في إكساب التلاميذ للمفاهيم العلمية"

والقد كان المدف من هذه الدراسة التحدث عن أثر الرسوم المتحركة في تشكيل شخصية

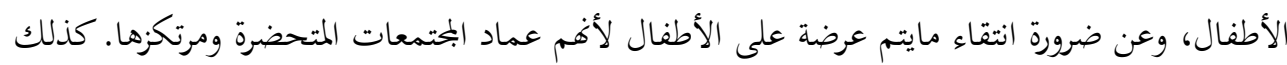

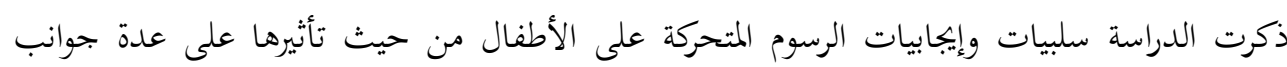

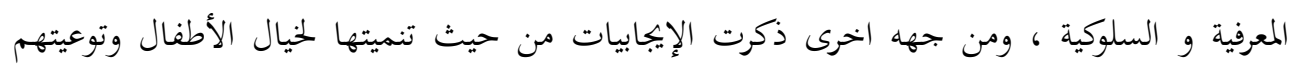

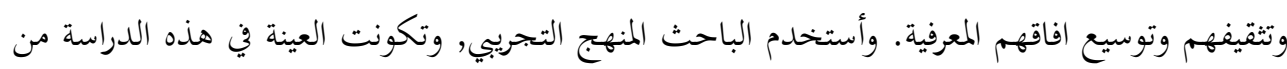

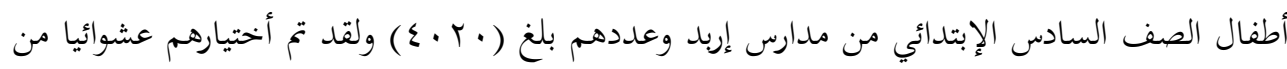

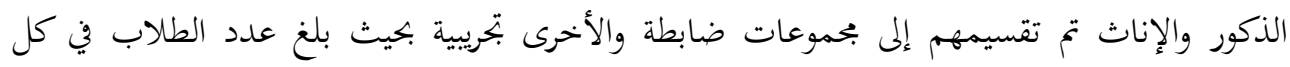

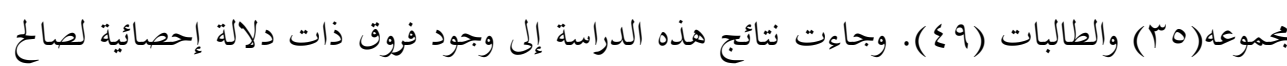
الأناث في اختبار اكساب المفاهيم العلمية. والطبات (عاءت 
دراسـة شعبان و بـن عيسى (1 | ( Y) بعنوان " أثر الرسوم المتحركة في تنميـة السلوك العدواني للطفل الجزائري"

هدفت هذه الدراسة إلى معرفة أثر الرسوم المتحركة في سلوك الأطفال ووصف هذا السلوك أما إيجابي أو سلبي كما وضحت هذه الدراسة بعض من مظاهر العنف والعدوان التي تحتوي عليها الرسوم

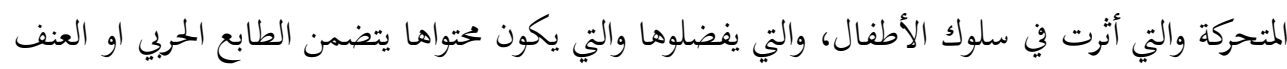
والضرب وأنتصار البطل, كما أستخدم الباحثين المنهج الوصفي التحليلي ليصفو الظاهره كما في الواقع، والمنهج الكمي ليقومو بالمقارنة وبهدف قياس الظاهرة موضوع الدراسة. وبلغت عينه الدراسة (· I ( )

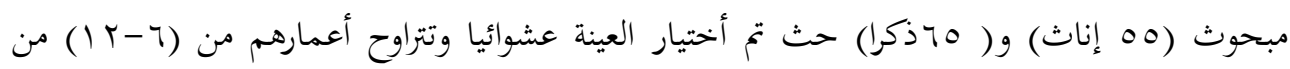
التلاميذ في المدارس الإبتدائية. كما استخدم الباحثين في هذه الدراسة العديد من الأدوات كالملاحظة والمقابلة. ومن نتائج هذه الدراسة أن اغلب افراد العينة يشاهدون الرسوم المتحركة بدون رقابة من أولياء امورهم وعدم مبالاة منهم، وهذا ساعد على تنمية السلوك العدواني نتيجة عدم الرقابة وأيضا وجد ان العنف الجسدي يجسدة الأطفال الذكور بينما يمارس الأناث العنف اللفظي. كما أن أغلب المبحوثين يمارسون العنف مع أخوقم إذا لم تتوفر الرقابة من اولياء الأمور.

دراسـة مكيري، ماليـة(1 1 • ب) بعنـوان "تأثير مضـامين الرسوم المتحركة على سـلوكيات الأطفـال

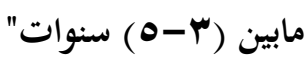
ولقد هدفت هذه الدراسة إلى تناول بعض صور العنف في الرسوم المتحركة وأثرها على سلوك الطفل.من حيث إيجابيات وسلبيات مشاهدة الرسوم المتحركة، خصائص مشاهدة أطفال مرحلة الطفولة المبكرة للرسوم المتحركة. كما أشارت هذه الدراسة إلى بعض أسماء الرسوم المتحركة التى تحتوى على

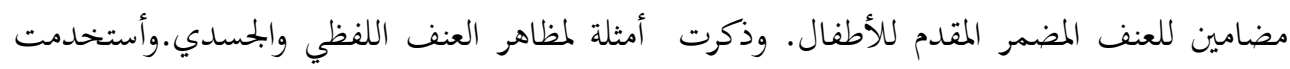
الباحثة المنهج الوصفي التحليلي. وتكونت عينة الدراسة من أباء وأمهات الأطفال الذين تترراوح أعمارهم مابين(r-0) سنوات وقد بلغ حجم العينه (• ا ( ). ولقد قام الباحث بوضع أستمارة تحتوي على أسئله مفتوحة ومغلقه, وأجرت هذه الدراسة تحليل لبعض محتويات الرسوم المتحركة لمعرفة أهدافها وزمنها وقسمتها لفئات مختلفة. وأسفرت نتائج هذه الدراسة على أن الأمهات أكثر دراية وعلم بالمحالات التي يمكن أن يقلد فيها الطفل مايشاهدة من سلوكيات وذلك بحكم أفن أكثر أتصالا بالطفل على عكس وفس ولى الأباء الذين ينشغلون بأعمالهم خارج المنزل، كما أوضحت النتائج إلى أن المستوى التعليمي للأباء 


\section{المجلة العلمية لكلية رياض الاطفال - جامعة اسيوط}

والأمهات له دور كبير في تحديد أكثر المجالات التي يتجلى فيها تقليد الأطفال للسلوكيات العنيفة

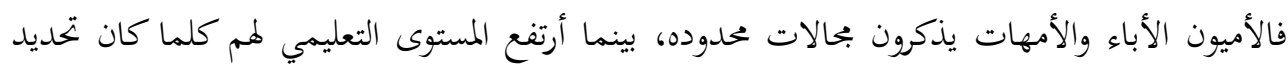

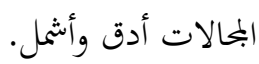

دراسة الجبري، أسماء، والسبيهين، أمجاد(0 + † ب بعنوان " الأثار اللإيجابية والسلبية للألعاب

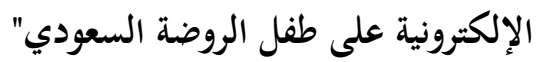

والتي كان هدفها التعرف على الأثار السلبية للألعاب الإلكرتونية أو الرسوم المتحركة ثلاثية

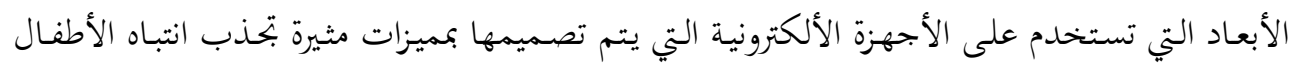

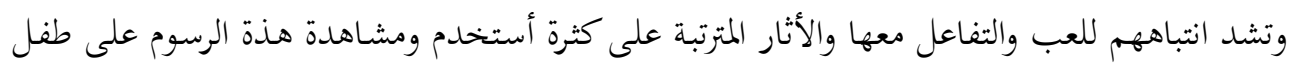
الروضة السعودي. كما أشارت إلى إيهابيات هذة الألعاب والرسوم المتحركة على العمليات المعرفية والأثار

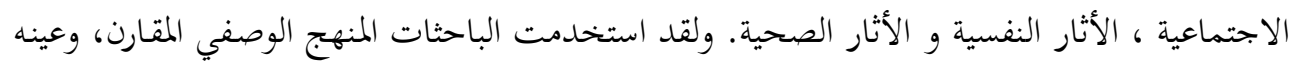

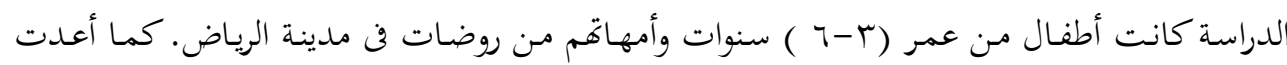

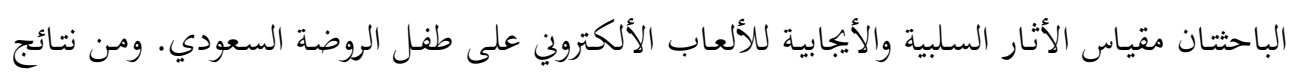

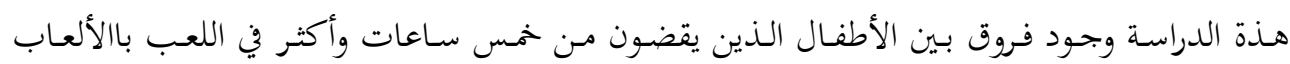
الألكترونية فكلما زادت نسبة المشاهده ، زاد التأثير السلبي.

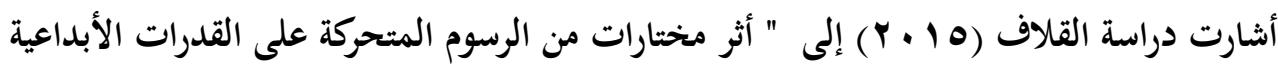
لدى الأطفال الموهوبين في مرحلة رياض الأطفال

هدفت هذه الدراسة إلى التعريف بتأثير التلفاز والرسوم المتحركة على الأطفال ووضحتها في

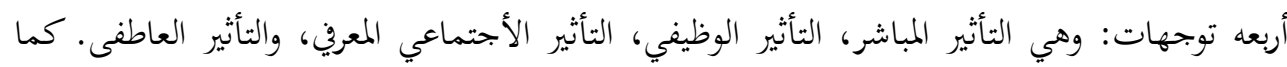

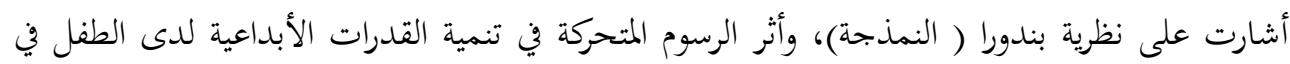

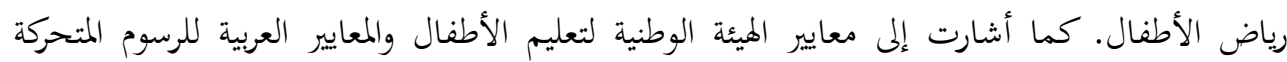

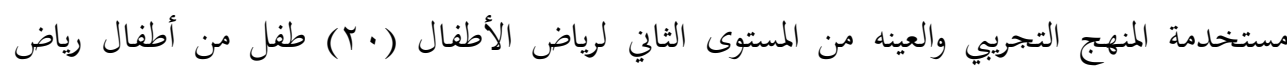
الأطفال بدولة الكويت. ولقد استخدمت الباحثة أدوات وهي : قائمة خصائص الأطفال الموهوبين

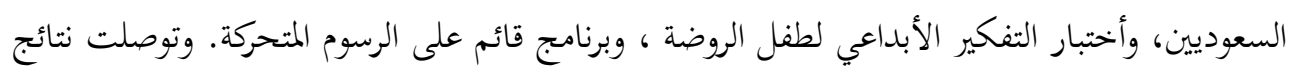

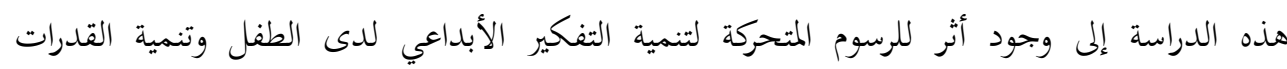

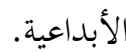


وفي دراسه قام بها كابينار (2005) Kabapinar "عنوانها الثدريس الفعال للمفاهيم بواسطة الكرتون من وجهه نظر الطريقة البنائية"

حيث قدمت هذه الدراسة طريقة مفاهيم الكرتون (Cartoon concept Approach) التي أستخدمت كطريقة في التعليم ولقد أخذ بعين الأعتبار وجهه نظر النظرية البنائية في تعلم العلوم.

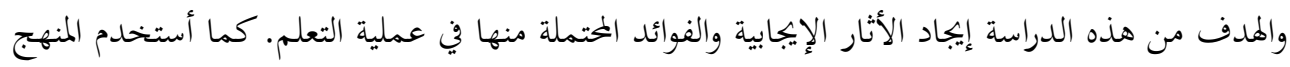

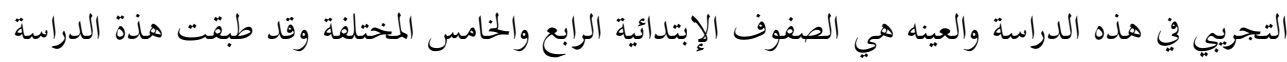

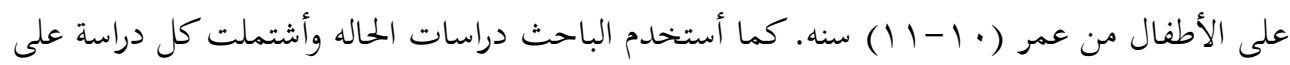

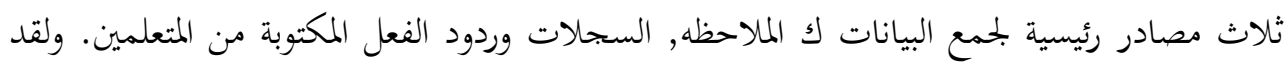

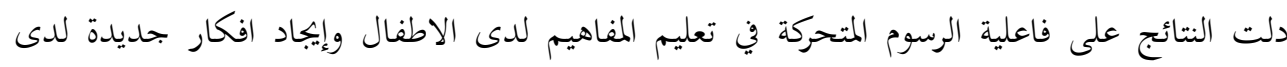

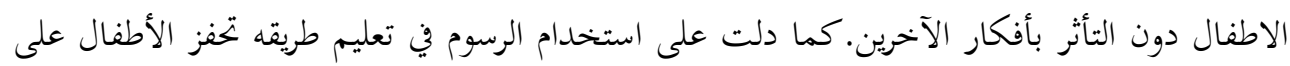

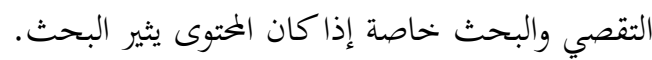

وفي دراسة قامت بها سودها (2011) Sudha بعنوان" العوامل المؤثرة على التغيير في سلوك الأطفال عند عرض برامج الرسوم المتحركة". هدفت دراسة سودها بتحليل العوامل التي تؤثر على الأطفال عند مشاهدة برامج الرسوم

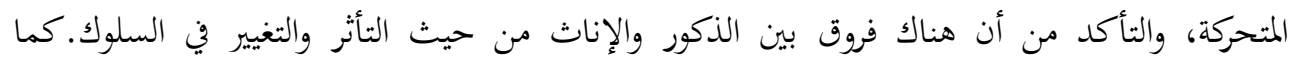

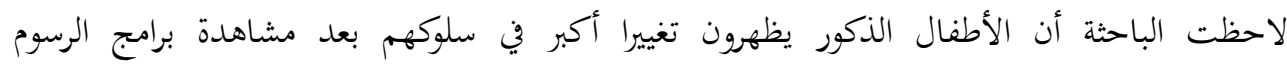

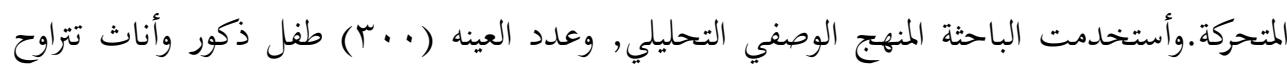

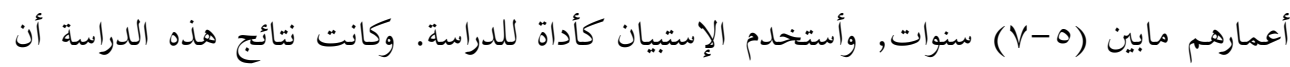
الرسوم المتحركة التعليمية لعبت دور هام في تعليم الحروف الأبجدية والأرقام وقواعد السلامه في الحياة . 
وفي دراسـة قـام بهـا حسن (2013) Hassan بعنسوان" تأثير الرسوم المتحركسة على سـلوك

الأطفال الذين يذهبون للمدرسة"

وأهتمت دراسة حسن(2013) Hassan بالإشارة إلى مدى تأثير الرسوم المتحركة في

سلوكيات الأطفال. وتعتبر هذة الدراة مسحية, ولقد بلغ حجم العينة (. (1) ذكور وإناث واعمارهم

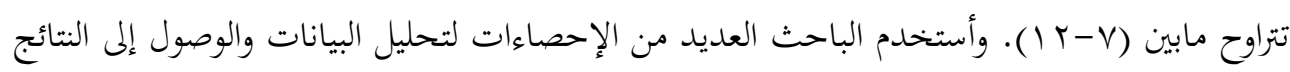

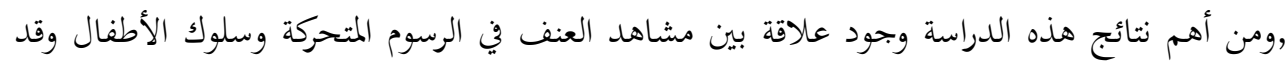

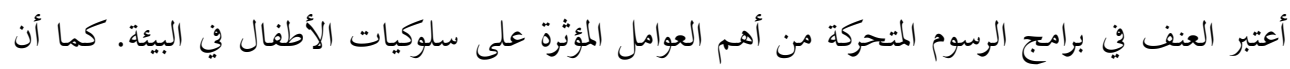
للرسوم المتحركة تأثير قوي على الأطفال واسلوب حياهم ولغتهم وسلوكهم العدوائ.

دراسة حبيب وسليمان (T\& Soliman،Habib(2015، T. بعنوان " تأثير الرسوم المتحركة في سلوك الأطفال واستجاباتهم العقلية".

هدفت هذه الدراسة إلى الإشارة إلى إيهابيات مشاهدة الرسوم المتحركة وسلبياها أعتمادا على

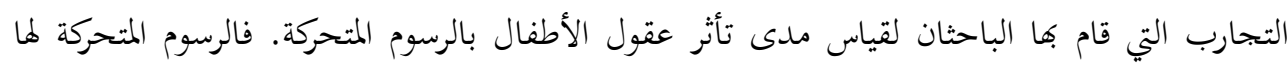

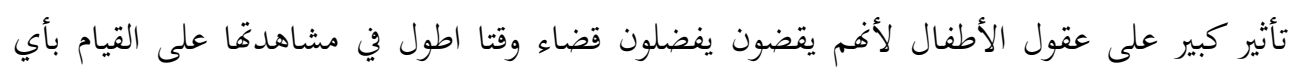

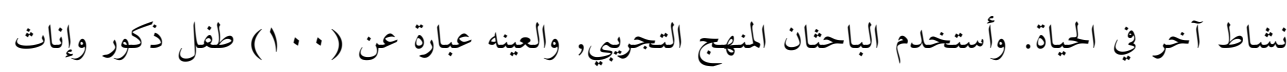

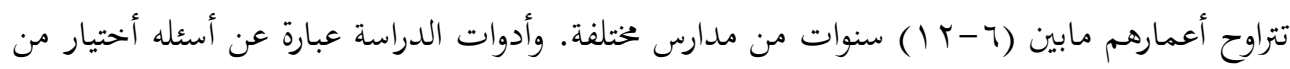

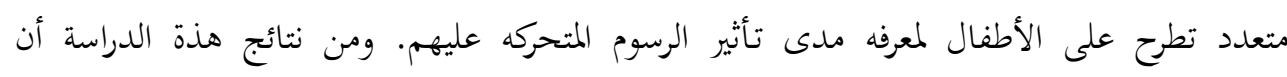

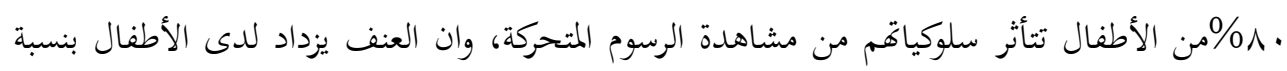

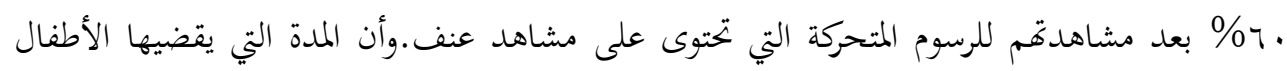
غالبا في مشاهدة الرسوم المتحركة يوميا أربع ساعات أو اكثر وهي أفضل لئل وسيلة للتسلية. التعقيب على الدراسات السابقه:

من خلال استعراض الباحثة للدراسات السابقة تبين أن هناك اهتماماً متزايداً من قبل الباحثين

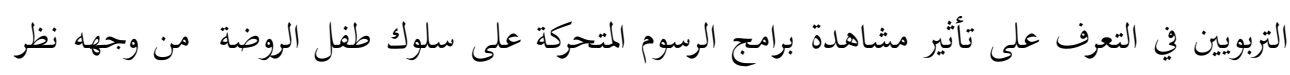

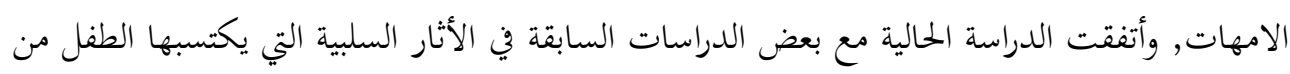

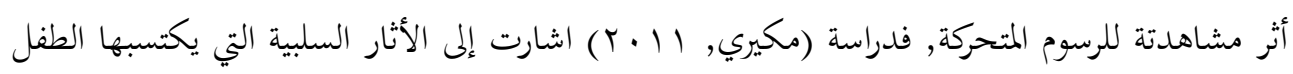


من الرسوم المتحركة مثل إكتسابة للثقافة والعادات الأجنبية. وتتفق كذلك دراسة (شعبان و بن عيسى,

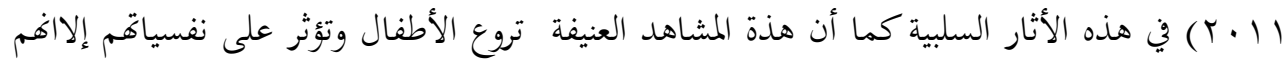
يعتادون عليها تدريجيا , وتشجع الأطفال على الجريمة وعلى وتقليدها. وكذلك دراسة (حسن ,2013) Hassan

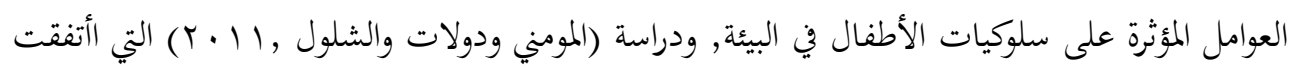
مع الدراسة الحالية من حيث أثر الرسوم المتحركة في تشكيل شخصية الأطفال, وعن ضرورة انتقاء مايتم عرضة على الأطفال لأفم عماد المجتمعات المتحضرة ومرتكزها. وجاءت دراسة (الحبري, والسبيهين,0 1 • ب) مؤكده سلبيات الألعاب الألكترونية وإيجابياها من حيث أن الألعاب الألكترونية تحتوي على رسوم متحركة وهي التي تحذب الأطفال للمارستها. وكما في دراسة الحولي (ع . . ب) ودراسة

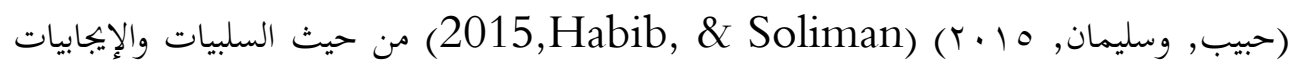
التي يكتسبها الطفل من خلال مشاهدتة للرسوم المتحركة وتأثيرها على سلوك الأطفال. ودراسه (كابينار Kabapinar (2005, ودراسة (سودها Sudha 2011 من حيث أشارت إلى أن الرسوم المتحركة التعليمية لعبت دور هام

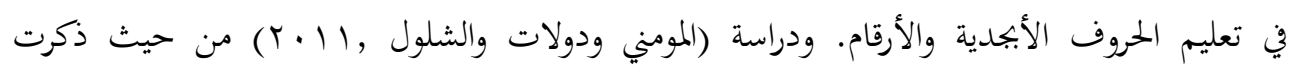
ايجابيات الرسوم المتحركة من حيث تنميتها لخيال الأطفال وتوعيتهم وتثقيفهم وتوسيع افاقهم المعرفية.

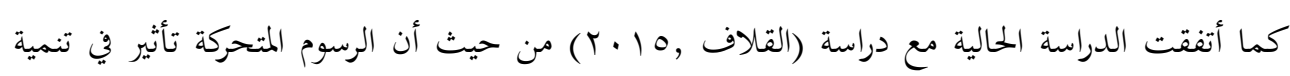
القدرات الأبداعية لدى الطفل وهذا يعتبر من إيجابياتما.

$$
\text { منهج الدراسة واجراءاته: }
$$
استخدم المنهج الوصفي الارتباطي للتحقق من فروض البحث وتساؤلاته ثانياً: مجتمع الدراسة وعينته: تكون بحتع الدراسة الحالية من أمهات اطفال الروضة في مدينة الرياض وفي مدراس التربية

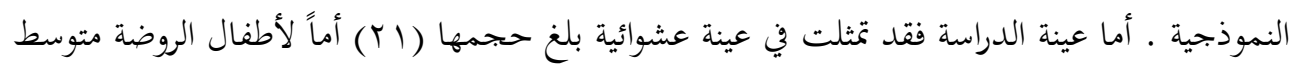

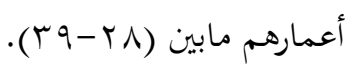


ثالثاً: أداة الدراسة:

تكونت الاستبانة في صورتا النهائية من ثلاثة أجزاء وهي:

أ- الجزء الأول: ويشتمل على البيانات الأولية للأم والتي تمثلت في المستوى التعليمي. ب- الجـزء الثـاني: ويشـتمل على البيانـات الأساسية للطفـل، والتي تمثلـت في (عـدد سـاعات مشـاهدة الطفـل للرسـوم المتحركـة في اليوم، اللغـة المسـتخدمة في بـرامج الرسـوم المتحركـة التي

يشاهدها الطفل).

ج- الجزء الثالث: تكون هذا الجزء من محورين وهما كالتالي:

- المحور الأول: دور الرسوم المتحركة في تشكيل سلوك طفل الروضة (السلبي)،

ويشتمل هذا المحور على (T ب) فقرة..

- المحور الثاني: إيجابيات الرسوم المتحركة في تشكيل سلوك طفل الروضة، ويشتمل فئل

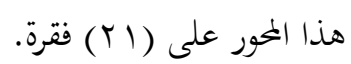

وقد روعي عند تصميم الاستبانة البساطة والسهولة، على أن تكون الإجابة عليها وفقاً لمقياس ليكرت الثلاثي (غير متوفرة، متوفرة إلى حد ما، متوفرة بشكل كبير). بحيث تم منح الإجابة على (متوفرة بشكل كبير) درجتان، (متوفرة إلى حد ما) درجة واحدة، (غير متوفرة) صفر . وقد تبنت الباحثة في إعداد المحاور الشكل المغلق (Closed Questionnaire) الذي يحدد الاستجابات المحتملة لكل سؤال.

رابعاً: صدق أداة الدراسة:

ب- صدق الاتساق الداخلي لأداة الدراسة:

بحساب معامل الارتباط بيرسون "Pearson Correlation" لمعرفة الصدق الداخلي

للاستبانة وذلك عن طريق حساب معامل الارتباط بين درجة كل فقرة من فقرات الاستبانة بالدرجة الكلية

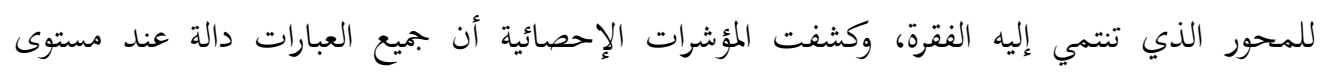
( ا . . )، وبعضها دال عند مستوى (0 . . )، وهو ما يوضح أن جميع الفقرات المكونة للمحور الثاني (إيجابيات الرسوم المتحركة في تشكيل سلوك طفل الروضة) تتمتع بدرجة صدق عالية، تحعل الاستبانة صالحة للتطبيق الميداين. 
من خهلال النتائج اتضـح أن معامل الثبات الفاكرونباخ للمحور الأول بلغ (1 ب, · )، بينما بلغ

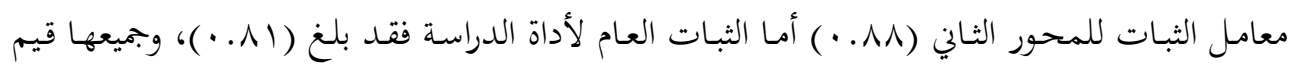
ثبات مرتفعة توضح صلاحية أداة الدراسة للتطبيق الميداني.

\section{سادساً:أساليب المعالجة الإحصائية:}

لتحقيق أهداف الدراسة وتحليل البيانات التي تم تحميعها، فقد تم استخدام العديد من الأساليب الإحصائية المناسبة التالية:

التكرارات والنسب المئوية:والمتوسط الحسابي والانحراف المعياري

نتائج الدراسة

تفسير نتائج الدراسة الخاصة بمدى تحقق الفرض الأول :توجد علاقة بين مشاهدة طفل الروضة

$$
\text { للرسوم المتحركة والسلوك السلبي له }
$$

أ- يوجد بتحانس في درجة موافقة الأمهات على دور الرسوم المتحركة في تشكيل سلوك طفل الروضة

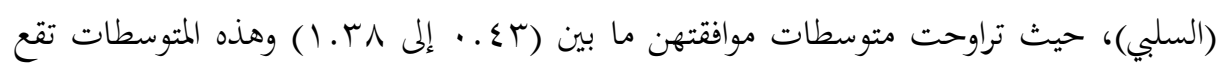
بالفئة الثانية من المقياس المتدرج الثلاثي والتي تشير إلى درجة متوفرة إلى حد ما، حيث يتبين من النتائج الموضحة بالجدول أعلاه أن أمهات رياض الأطفال بمدينة الرياض يرون أن جميع العبارات

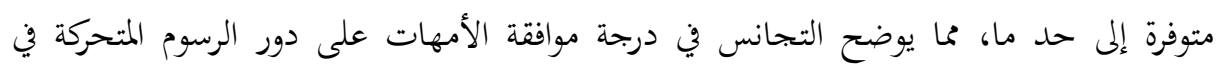
تشكيل سلوك طفل الروضة السلبي. وفيما يلي أعلى ثلاث عبارات وأدنى عبارتين وفقاً لأعلى قيم للمتوسط الحسابي، وأدنى قيم للانحراف المعياري في حالة تساوي المتوسطات الحسابية: ا ـ جاءت العبارة رقم (· ·) وهي "يرسخ القيم الأجنبية بشكل كبير" بالمرتبة الأولى بين

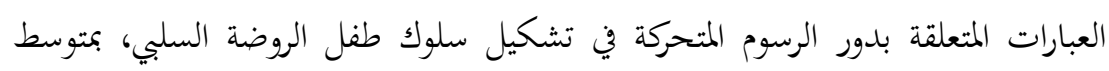

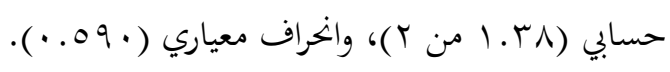




\section{المجلة العلمية لكلية رياض الاطفال - جامعة اسيوط}

Y. جاءت العبارة رقم (ع) وهي "يشجع على العمل الجماعي" بالمرتبة الثانية بين العبارات

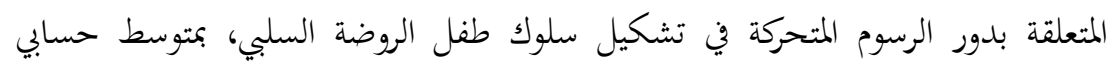

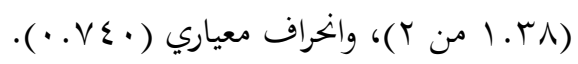

r. جاءت العبارة رقم (Tr) وهي " يتقمص الطفل الشخصيات التي يشاهدها من خلال

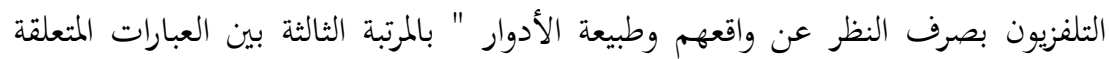

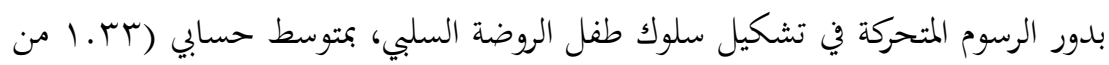

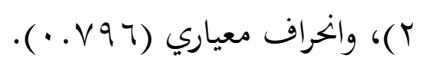

ع. جاءت العبارة رقم (9 1 ) وهي "يشجع على العنصرية" بالمرتبة الأخيرة بين العبارات المتعلقة

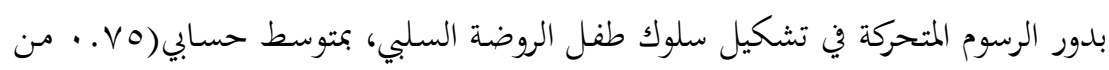

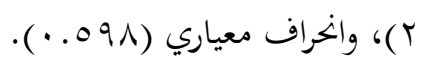

ه. جاءت العبارة رقم (9) وهي "يناسب المحتوى عادات وتقاليد المجتمع" بالمرتبة الأخيرة بين

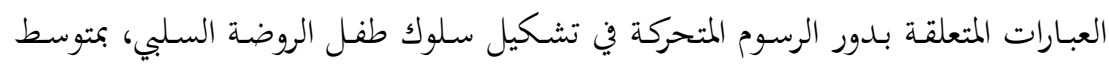

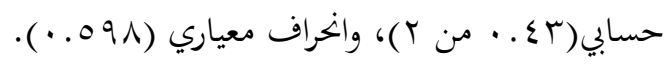

ب- بلغ المتوسط الحسابي العام للمحور المتعلق بدور الرسوم المتحركة في تشكيل سلوك طفل الروضة

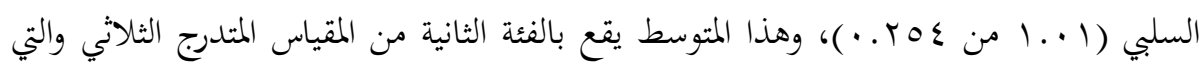

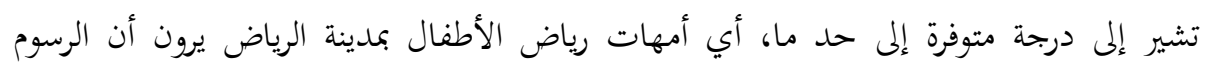
المتحركة تؤثر إلى حد ما في تشكيل السلوك السلبي لطفل الروضة.

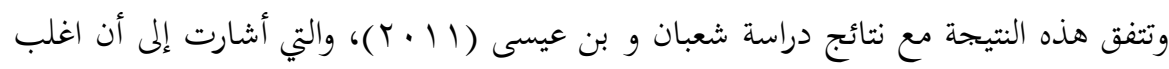

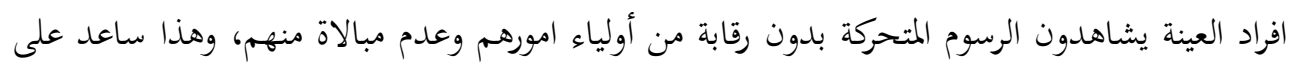

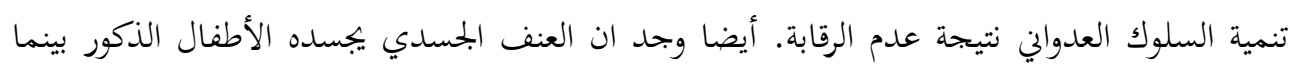

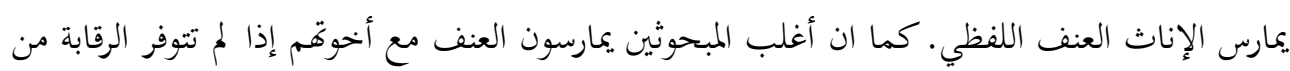

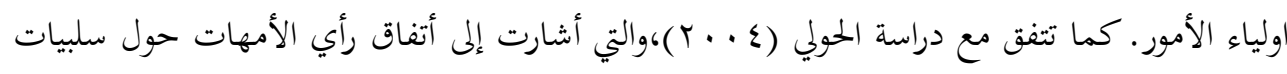

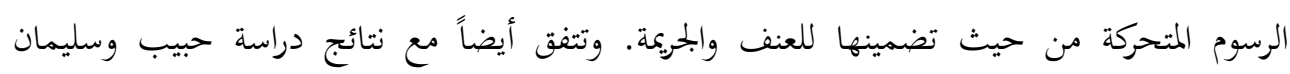

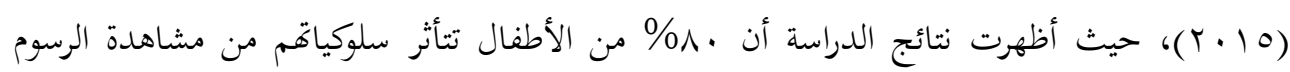

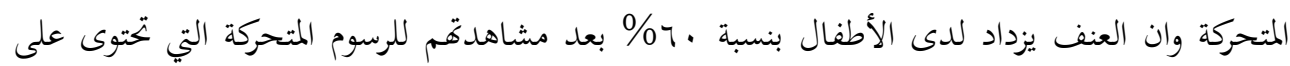


مشاهد عنف. ودراسة دراسة حسن (2013) Hassan، حيث أعتبر العنف في برامج الرسوم المتحركة

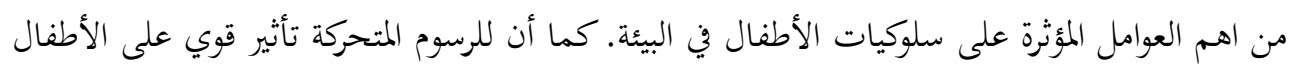
واسلوب حياتم ولغتهم وسلوكهم العدواني. تفسير نتائج صحة الفرض الثاني إلى وجود علاقة بين مشاهدة أطفال الروضة والسلوك الإيجابي لهم إلى :

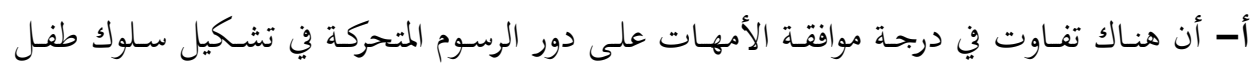

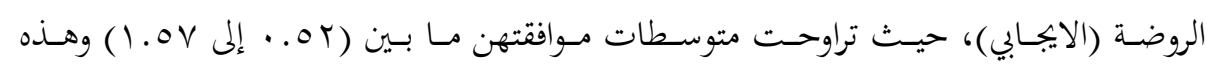

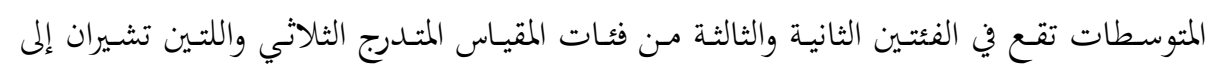

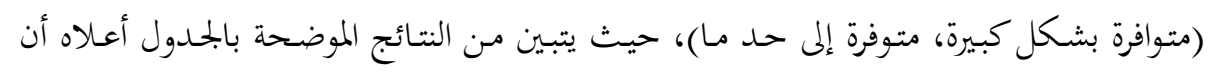

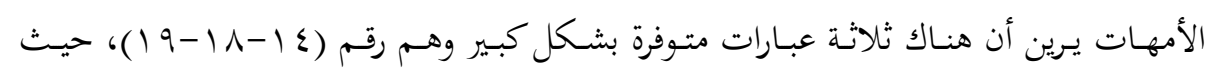

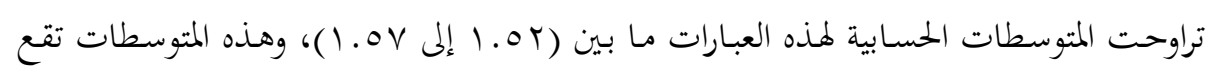

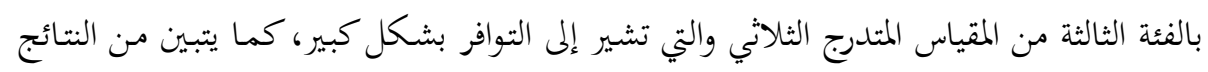

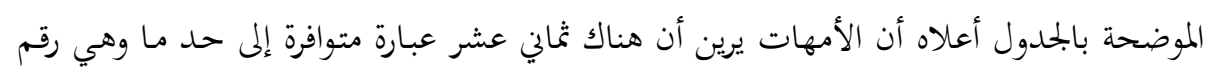

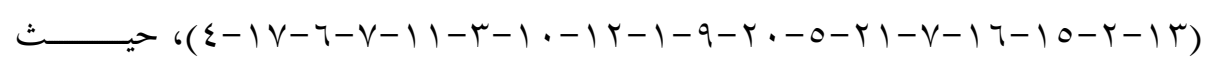

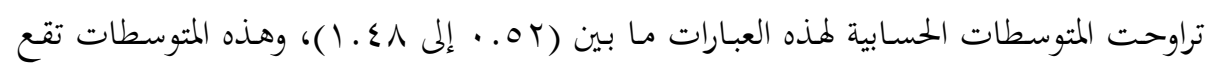

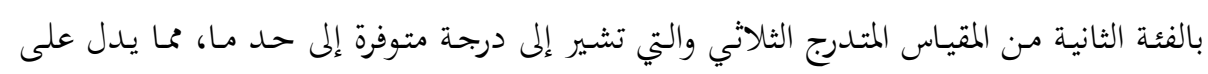
تفاوت وجهات نظر الأمهات على إيجابيات الرسوم المتحركة في تشكيل سلوك طفل الروضة.

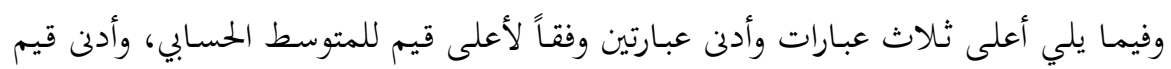
للانخراف المعياري في حالة تساوي المتوسطات الحسابية: 1 ا ـ جاءت العبارة رقم (ع 1) وهي" تعطي الطفل خبرات حياتيه مثل. التعرف على الطبيعة ولمظاهر

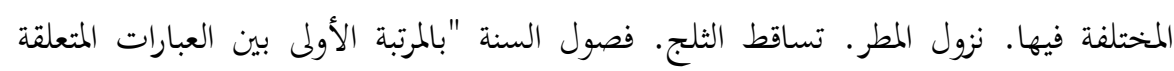

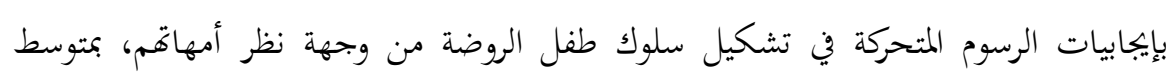

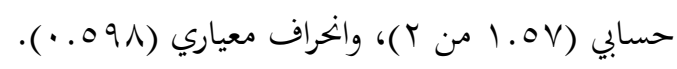




\section{المجلة العلمية لكلية رياض الاطفال - جامعة اسيوط}

Y. جاءت العبارة رقم (9 1) وهي" يكتسب الطفل اللغة وكلمات بسيطة من خلال مشاهدته للرسوم المتحركة" بالمرتبة الثانية بين العبارات المتعلقة بإيجابيات الرسوم المتحركة في تشكيل سلوك طفل الروضة من وجهة نظر أمهاهم، بمتوسط حسابي(1.OV من Y)، وانحراف معياري $\cdot(\cdot .0 \cdot v)$

ب. جاءت العبارة رقم (1 (1) وهي"يصبح الطفل كثير التساؤلات مما ينمى مدركاته المعرفية" بالمرتبة الثالثة بين العبارات المتعلقة بإيجابيات الرسوم المتحركة في تشكيل سلوك طفل الروضة من وجهة

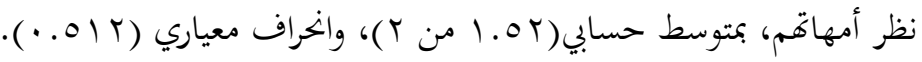

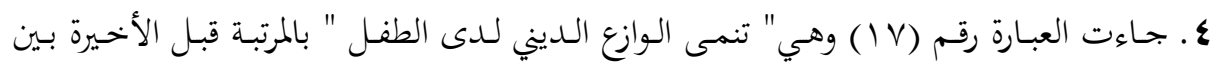
العبـارات المتعلقـة بإيجابيـات الرسوم المتحركة في تشـكيل سلوك طفـل الروضـة مـن وجهـة نظر

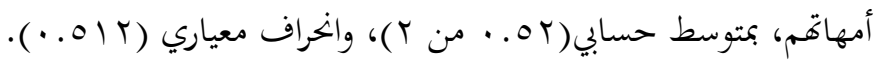
ه. جاءت العبارة رقم (ع) وهي "يردد الطفل بعض الألفاظ البذيئة بعد مشاهدته لهذه البرامج" بالمرتبة الأخيرة بين العبارات المتعلقة بإيجابيات الرسوم المتحركة في تشكيل سلوك طفل الروضة من وجهة نظر أمهاهم، بمتوسط حسابي(r ه. · من Y)، وانحراف معياري ( • V. • ). ب- بلغ المتوسط الحسابي العام للمحور المتعلق بإيجابيات الرسوم المتحركة في تشكيل سلوك طفل الروضة (7 ا ـ ا من بحس . •)، وهذا المتوسط يقع بالفئة الأولى من المقياس المتدرج الثلاثي والتي تشير إلى درجة متوفرة إلى حد ما، أي أمهات رياض الأطفال بمدينة الرياض موافقات إلى حد ما على إيجابيات الرسوم المتحركة في تشكيل سلوك طفل الروضة.

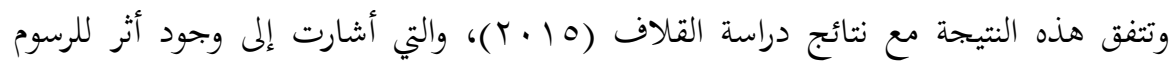
المتحركة إذا ما وضعت ضمن بربجية تربوية موجهه لتنمية التفكير الإبداعي لدى الطفل فالرسوم المتحركة

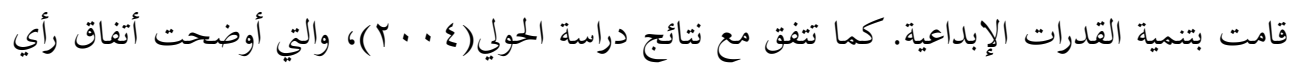
الأمهات وتحليل المحتوى للأفلام من حيث إيجابياتا في نشر بعض القيم كالتعاون. ودراسة سودها والتي أشارت إلى أن الرسوم المتحركة التعليمية لعبت دور هام في تعليم الحروف الأبجدية والأرقام وقواعد السلامة في الحياة ويساعد توفر عناصر اللون والحركة والصوت والصورة في برامج الرسوم المتحركة في تزويد الأطفال بالمعارف والمهارات المتعددة، كما تعمل على توعية الأطفال وتثقيفهم 
أ.د. كريمان بدير

أ. منيره بنت ناصر بن ابراهيم الصوينع بوير
تأثير مشاهدة برامج الرسوم المتحركة على سلوك أطفال الروضة من وجهه نظر الأمهات

وتوسيع أفاقهم الفكرية، وذلك من خلال تناول برامج الرسوم المتحركة للجوانب الاجتماعية والدينية والاقتصادية والصحية وغيرها

مدى تحقق صحة الفرض الثالث :

توجد علاقة ذات دلالة إحصائية بين سلوك أطفال الروضة الإيجابي وعدد الساعات التي يقضيها الطفل في مشاهدة الرسوم المتحركة

للتحقق من هذا الفرض والتعرف على ما إذا كانت هناك علاقة ذات دلالة إحصائية بين مشاهدة الرسوم المتحركة وبين سلوك طفل الروضة، استخرجت الباحثة معامل الارتباطباستخدام معادلة بيرسون، لحساب العلاقة بين متغيري الدراسة، يتبين من النتائج أنه لا توجد علاقة ذات دلالة إحصائية بين عدد الساعات التي يقضيها الطفل في مشاهدة الرسوم المتحركة والسلوك الإيجابي، حيث بلغت قيم

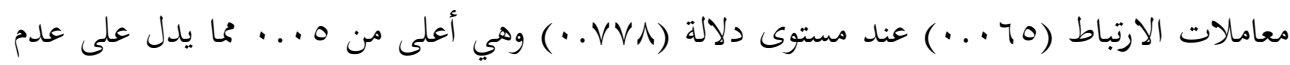
وجود علاقة دالة إحصائياً بين عدد الساعات التي يقضيها الطفل في مشاهدة الرسوم المتحركة والسلوك الإيجابي.

الفرض الرابع :توجد علاقة بين عدد ساعات المشاهدة والسلوك السلبي لأطفال الروضة كمـا يتبـين مـن النتائج أنه توجدعلاقة طرديـة ذات دلالـة إحصـائية بـين عدد السـاعات التي

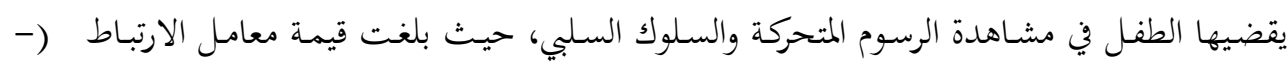
ع به . •)، عند مستوى دلالة ( ( . . . )، وهي قيمة أقل من ه . . . . مما يدل على وجود علاقة ذات دلالة إحصائية بين عدد الساعات التي يقضيها الطفل في مشاهدة الرسوم المتحركة والسلوك السلبي. اي أنه كلما زادت عدد ساعات مشاهدة الطفل للرسوم المتحركة كلما زاد السلوك السلبي، والعكس صحيح.

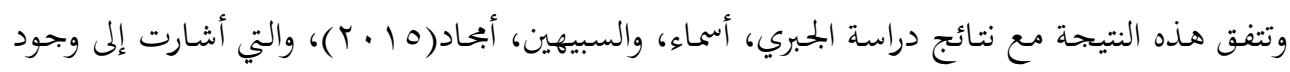
فروق بين الأطفال الذين يقضون من خمس ساعات وأكثر في اللعب بالألعاب الإلكترونية فكلما زادت نسبة المشاهدة، زاد التأثير السلبي. 
ثالثاً: التوصيات:

1. عقد ندوات لأمهات أطفال الروضات لتوعيتهم بكيفية تحسين سلوكيات أطفالهن، واختيار البرامج الكرتونية المناسبة التي لا تشكل سلوكيات سلبية لديهم.

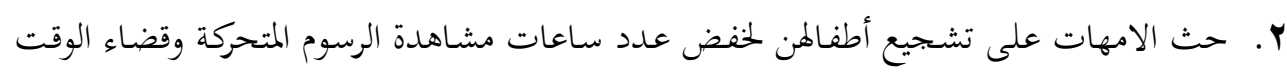

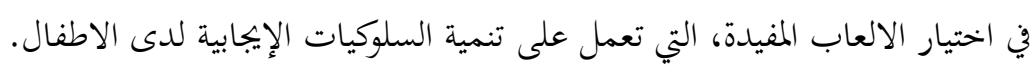
r. ب. تعليل مدة مشاهدة الأطفال للرسوم المتحركة. ع ـ إيجاد البرامج البديلة التي تعمق الثقافة الإسلامية هـ اختيار الأهل للبرامج التي يشاهدها الطفل، بالتوافق معهم، مع محاولة توجيهمم للبرامج التعليمية...

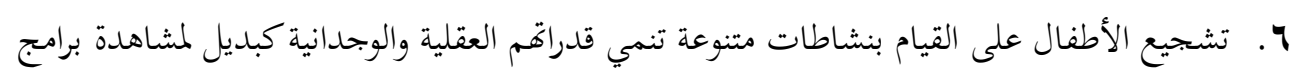
الرسوم المتحركة

مقترحات لدراسات مستقبلية:

ا-تأثير الرسوم المتحركة على القدرات الإبداعية لدى الأطفال الموهوبين في مرحلة رياض الأطفال. ץ-أثر استخدام رسوم متحركة في تدريس المواد التعليمية وإكساب التلاميذ للمفاهيم العلمية" 


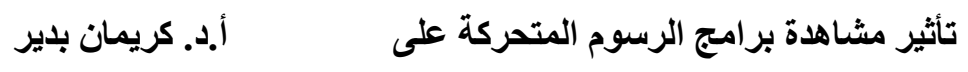

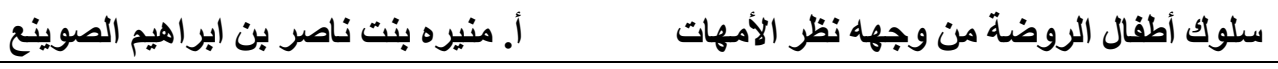

$$
\text { المراجع }
$$

$$
\text { أولاً: المراجع العربية }
$$

1- القلاف، خديجة،( (10 + ). أثر مختارات الرسوم المتحركة على القدرات الأبداعية لدى الأطفال الموهوبين

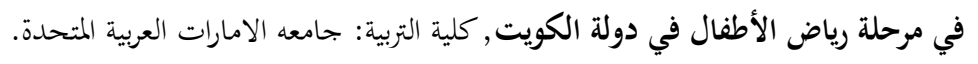

Y- الجبري, أسماء, السبيهين, أبحاد, (10 · ب). الأثار الإيجابية والسلبية للألعاب الإلكترونية على طفل الروضة

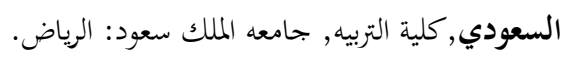

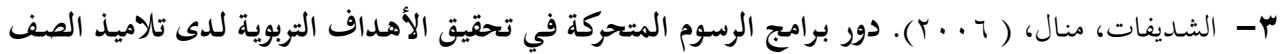
الثالث الأساسي من وجهة نظر المعلمين .رسالةماجستير غير منشورة، جامعة اليرموك، إربد، الأردن. ع- عبدالرمن، أسامة، (ع ا ب.). أثر الرسوم المتحركة على الأطفال، الجيزة: هبة النيل العربية للنشر والتوزيع. ه- شعبان، مهدية، بن عيسى، امال، (11) (1). أثر الرسوم المتحركة في تنمية السلوك العدواني للطفل الجزائري,

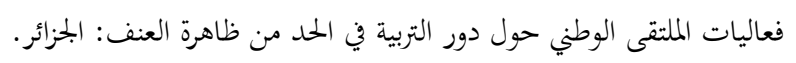

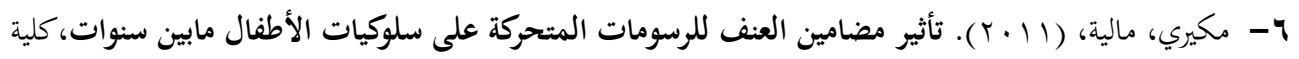
العلوم السياسية والإعلام: الجزائر. ثانياً: المراجع الاجنبية:

1- Habib، K \& Soliman،T(2015)"Cartoon's Effect in Changing Children Mental Response and Behavior". Open Journal of Social Sciences، $3 \cdot 248-264$

2- Kabapinar، F.(2005). Effectiveness of Teaching via Concept Cartoons from the Point of View of Constructivist Approach . Educational Sciences: Theory \& Practice ، 5(1) p-p 135-146.

3- Hassan، A. ‘ \& Daniyal، M. (2013). Cartoon Network and its Impact on Behavior of School Going Children: A Case Study of Bahawalpur Pakistan. International Journal of Management، Economics and Social Sciences 2(1)، 6-11. 